\title{
Production objectives and trait preferences of village poultry producers of Ethiopia: implications for designing breeding schemes utilizing indigenous chicken genetic resources
}

\author{
Nigussie Dana $\cdot$ Liesbeth H. van der Waaij • \\ Tadelle Dessie • Johan A. M. van Arendonk
}

Accepted: 14 May 2010/Published online: 29 May 2010

(C) The Author(s) 2010. This article is published with open access at Springerlink.com

\begin{abstract}
To generate information essential for the implementation of breeding schemes suitable for village poultry producers in Ethiopia, a survey was conducted aimed at defining the socioeconomic characteristics of the production environments in different geographic regions, understanding the important functions of chickens, identifying farmers' choice of chicken breeds and the underlying factors that determine the choice of genetic stock used. The survey included both questionnaire survey and a participatory group discussion. A total of 225 households (45 households from each of five Woredas) were interviewed. The questionnaire was designed to collect data covering general information on village poultry production such as socio-management characteristics, production objectives, population structure, breed choice and trait preferences, market preferences of specific traits, and farmers' selection practices. The participatory farmers' discussions were designed to involve stakeholders in defining the breeding objective "traits" and deriving their
\end{abstract}

\footnotetext{
N. Dana $(\bowtie)$

Ethiopian Agricultural Research Institute,

P.O. Box 32, Debre, Zeit, Ethiopia

e-mail: negussiedana@yahoo.com

N. Dana $\cdot$ J. A. M. van Arendonk

Animal Breeding and Genomics Centre, Wageningen University,

P.O. Box 338, 6700 AH Wageningen, The Netherlands

L. H. van der Waaij

Adaptation Physiology Group, Wageningen University,

P.O. Box 338, $6700 \mathrm{AH}$ Wageningen, The Netherlands

T. Dessie

International Livestock Research Institute,

P.O. Box 5689, Addis Ababa, Ethiopia
}

relative importance in the production environment based on the different functions of chickens and "traits" identified in the interviews. The results showed that production of eggs for consumption is the principal function of chickens in most regions followed by the use as source of income and meat for home consumption. The production system in all geographic regions studied revealed similar features generally characterized by extensive scavenging management, absence of immunization programs, increased risk of exposure of birds to disease and predators, and reproduction entirely based on uncontrolled natural mating and hatching of eggs using broody hens. Farmers' ratings of indigenous chickens with respect to modern breeds showed the highest significance of the adaptive traits in general, and the superior merits of indigenous chickens to high yielding exotic breeds in particular. Adaptation to the production environment was the most important attribute of chickens in all the study areas. The high significance attributed to reproduction traits indicates the need for maintaining broody behavior and high level of hatchability while breeding for improved productivity of indigenous chickens for village conditions. The market price of chickens is primarily dictated by weight, but farmers rated growth (males) and number of eggs followed by growth (females) as the production traits they would like the most to be improved. Therefore, the ultimate breeding goal should be to develop a dual-purpose breed based on indigenous chicken genetic resources with any of the comb types other than single for all the regions studied having the most preferred white body plumage for farmers in the Amhara region and red body plumage for those in Oromia, Benshangul-Gumuz, and Southern regions.

Keywords Indigenous chickens · Breeding objectives . Trait preference Ethiopia 


\section{Introduction}

Increased productivity of the poultry subsector by using exotic breeds in Ethiopia failed to become a sustainable option mainly because this strategy recurrently faced the problem of birds not being adopted widely by the rural farmers due to several socioeconomic and environmental challenges (Teklewold et al. 2006). The management conditions under which the animals are produced vary along the existing production systems which were broadly classified into the village, small-scale commercial, and large-scale commercial systems based on flock size, production objectives, and level of specialization and/or technology use (FAO 2008). A review by Gueye (1998) indicated that nearly $80 \%$ of the estimated 1.3 billion chickens in Africa comprise indigenous breeds raised by village farmers under extensive systems. In Ethiopia, the village system contributes to more than $90 \%$ of the national chicken meat and egg output. This system is generally characterized by small size of unimproved indigenous flock per household, birds maintained under scavenging regimens in the backyards with little or no supplemental feeding, no separate shelters except for night enclosures in the family house, and lack of health care.

Despite their importance indigenous breeds are under threat due to various factors such as changing production systems and indiscriminate crossbreeding (Besbes 2009). There are very few examples of breeding programs for indigenous breeds in Africa and around the world. Recently a genetic improvement program has been initiated for increasing productivity of indigenous chickens of Ethiopia through selective breeding, as a means both to improve the livelihood of poor people as well as conserve the existing genetic diversity through utilization. Developing appropriate animal breeding programs for village conditions requires defining the production environments and identifying the breeding practices, production objectives, and trait choices of rural farmers (Solkner et al. 1998).

The traits traditionally considered as criteria for selecting breeding stock are important in describing the adaptive attributes and genetic merits of the indigenous chickens and in identifying farmers' choice of chicken breeds and the underlying factors that determine the choice of genetic stock used. The market preferences for specific traits identified in the current study could be used to compliment or stimulate further work on economic valuation of the traits (Scarpa 1999). However, even in the absence of economic values, the results could be used to simulate alternative breeding schemes by using appropriate genetic parameters and deriving relative weights for the breeding objective traits using the desired-gain selection-index method as suggested by Solkner et al. (2008). Solomon (2008) found that farmers' ratings of trait categories they preferred to be improved in sheep in traditional systems were based on economic grounds and could be translated into economic weights that are comparable to economic values derived from profit equations. A similar approach could be adapted for developing breeding systems for indigenous poultry.

The objectives of this study were (1) to identify the socioeconomic characteristics of the production environments in different geographic regions, (2) to gain understanding of the traditional selection practices, and (3) to identify and prioritize the breeding objectives and trait preferences of village producers through a participatory approach.

\section{Material and methods}

In each of the study regions two types of data collection were applied. Firstly, individual farmers were interviewed and a list of detailed information was obtained. Secondly, and based on the results of the individual interviews, farmers were asked to discuss in groups on what they considered as most important regarding selection decisions and market value.

\section{Description of study sites}

The survey sites were selected considering agro-ecology, socioeconomic significance of chicken production, and population of indigenous chickens based on the atlas published jointly by IFPRI and CSA (2006). Five Woredas (district) were covered in the study: Farta, Mandura, Horro, Konso, and Sheka. The ecological and demographic features of the study areas were described in Tables 1 and 2.

Data collection and analysis

The interview was designed to collect two sets of data. The first set covered general information on household characteristics and poultry holdings. The second set included data on more specific aspects of village poultry production such as socio-management characteristics, production objectives, population structure, breed choice and trait preferences, market preferences of specific traits, and farmers' selection practices. A total of 225 households (45 households from each Woreda) were interviewed. The interview data were analyzed using descriptive statistics, and the percentage of respondents was reported for each parameter.

The subsequent participatory farmers' discussions were designed to involve stakeholders in identifying the breeding objective "traits" and deriving their relative importance in the different production environments. In total seven independent groups of farmers were formed in each region, where each group comprised of five to seven members. The 
Table 1 Ecological characteristics and human and chicken populations of sampling areas (Woreda ${ }^{\mathrm{b}}$ )

\begin{tabular}{|c|c|c|c|c|c|}
\hline Ecology & $\begin{array}{l}\text { Farta } \\
\text { Cool to } \\
\text { very cold } \\
\text { submoist }\end{array}$ & $\begin{array}{l}\text { Mandura } \\
\text { Hot, } \\
\text { subhumid } \\
\text { lowland }\end{array}$ & $\begin{array}{l}\text { Horro } \\
\text { Tepid to } \\
\text { cool wet } \\
\text { highland }\end{array}$ & $\begin{array}{l}\text { Konso } \\
\text { Humid } \\
\text { lowland } \\
\text { to wet } \\
\text { highland }\end{array}$ & $\begin{array}{l}\text { Sheka } \\
\text { Cool wet } \\
\text { highland }\end{array}$ \\
\hline Altitude (range, $\mathrm{m}$ a.s.l., for sampling sites) & $2,700-2,870$ & $1,047-1,426$ & $2,580-2,810$ & $1,471-1,898$ & 2,285 \\
\hline Annual RF (mm) & $1,250-1,599$ & $900-1,300$ & $1,200-1,800$ & $500-700$ & $1,400-2,000$ \\
\hline Mean annual temp. $\left({ }^{\circ} \mathrm{C}\right)$ & $9-25$ & $25-32$ & $22-26$ & $24-37$ & $13-25$ \\
\hline Human population & 256,513 & 31,000 & 84,596 & 206,607 & 47,955 \\
\hline Average family size & 7 & 5 & 6 & 5 & 7 \\
\hline Total number of chickens & 136,410 & 23,186 & 34,991 & 107,588 & 50,491 \\
\hline Number of indigenous chickens & 123,869 & 21,171 & 29,780 & 86071 & 46,456 \\
\hline Number of exotic chickens ${ }^{a}$ & 12,541 & 2,015 & 5,211 & 21,518 & 4,035 \\
\hline Average flock size/household & 3.7 & 3.7 & 2.5 & 2.6 & 7.4 \\
\hline
\end{tabular}

${ }^{a}$ Exotic chickens distributed by the office of Agriculture since 2005 (this study was conducted in 2007)

${ }^{\mathrm{b}}$ Woreda is an administrative domain at the third level down a "Region" and immediately below a "Zone"

groups consisted of neighboring farmers following a transect walk in the villages. In order to address the variations in the opinions of farmers in different agroecological regions, the production system was classified into two "sub-systems": low altitude and high altitude systems. Three regions were selected to represent the two "sub-systems" (Mandura for the low altitude and, Farta and Horro for the high altitude production "sub-system").

As point of departure for the discussions, the results of the individual interviews were summarized according to (1) identified overall objectives of keeping chickens (egg or meat production, income generation, cultural/religious roles), (2) "traits" affecting consumer preferences in purchasing and/or selling chickens (live weight, plumage color, comb type), (3) "traits" farmers desired to be considered in improving village chickens (adaptation, growth, egg production, plumage color, "qumena," comb type, reproduction). The "traits" were defined in composite terms such as "adaptation" (comprising disease and stress tolerance, flightiness/ ability to escape predators, scavenging vigor), "live weight/ growth" (weight gain, live weight at market age/adulthood), "egg production" (annual egg number, persistency of egg laying), "reproduction" (broodiness, hatchability of eggs), and "qumena" (conformation/erectness, visual attraction/ color, size). Farmers who had adopted exotic chickens (i.e., modern, genetically improved chickens, mainly Rhode Island Red) were asked to rate their opinions on the comparative production, reproduction, and behavioral performance of indigenous chickens with respect to modern ones.

The discussions were aimed at coming to consensus regarding the ranking of the traits in the three categories, and in some cases, on the preference for indigenous or exotic chickens. Per category, a list of the different functions of chickens and "traits" identified in the interviews was prepared into separate flip charts and presented to each group for rating them according to their order of importance. The ratings were carried out by assigning different weights, ranging from 1 to 4 for the different functions of

Table 2 Demographic characteristics of sample households ( $\%$ of respondents)

\begin{tabular}{|c|c|c|c|c|c|c|}
\hline & Farta & Mandura & Horro & Konso & Sheka & Total \\
\hline Male household head & 68.9 & 71.1 & 91.1 & 95.5 & 68.9 & 79 \\
\hline Female household head & 31.1 & 28.9 & 8.9 & 4.5 & 31.1 & 21 \\
\hline Illiterate & 60 & 44.4 & 8.9 & 48.9 & 15.6 & 35.6 \\
\hline Read and write & 15.6 & 2.2 & 13.3 & 4.4 & 4.4 & 8 \\
\hline Elementary+above & 24.4 & 53.3 & 77.8 & 46.7 & 80 & 56.4 \\
\hline Muslim & 0 & 17.1 & 2.4 & 0 & 0 & 3.8 \\
\hline Christian & 100 & 75.6 & 97.6 & 81.6 & 100 & 87.6 \\
\hline Traditional & 0 & 7.3 & 0 & 5.3 & 0 & 2.4 \\
\hline Major ethnic community & Amhara (100) & $\begin{array}{c}\text { Amhara (44) Gumuz (28) } \\
\text { Agew (19) Oromo (7) }\end{array}$ & Oromo (100) & Konso (96) & $\begin{array}{l}\text { Shaka (84) } \\
\text { Kaffa (7) Menja (5) }\end{array}$ & \\
\hline
\end{tabular}


chickens and "traits" affecting market preferences and, weights $1-5$ and $1-7$, respectively, to rate the relative importance of the "traits" farmers desired to be improved in males and females (the highest weight $=$ most important, the lowest weight $=$ least important). Each group discussed thoroughly and assigned relative weights, on consensus or majority vote otherwise, with the aid of a facilitator. Averages of the relative weights assigned by the groups in each region were finally ranked and compared using Wilcoxon signed ranks test.

To get an impression on the viability of the populations, the effective population size was determined (Falconer and MacKay 1996):

$\mathrm{Ne}=(4 \times \mathrm{Nm} \times \mathrm{Nf}) /(\mathrm{Nm}+\mathrm{Nf})$

and the increase in inbreeding per generation as

$\Delta F=1 /(2 \mathrm{Ne})$

where $\mathrm{Ne}$ is the effective population size, $\mathrm{Nm}$ the number of breeding males, $\mathrm{Nf}$ the number of breeding females, and $\Delta F$ the inbreeding coefficient.

\section{Results}

Family and farm characteristics

The majority of the respondents were Christian males with at least elementary level of education (Table 1). Eight ethnic communities were comprised in the five survey sites. Except in Mandura, where the community was found to be a mixture of three communities other than the local Gumuz community $(27.9 \%)$, all the other geographic regions were populated almost entirely by specific communities native to that area (Table 2).

Functions of chickens

Except in Mandura and Horro, where chickens are raised importantly as source of income, egg production (for home consumption) is the most important reason for keeping chickens in all regions studied. Meat production (for home consumption) is second in importance in Oromia (Horro) and Southern regions. The function of chickens as source of cash income was rated to be as important as (Horro) or more important than egg and meat production (Mandura). It is second in importance to egg production in Farta. In Konso, the principal purpose of raising chickens is for home consumption and their value as income source is third in importance. Only about 5\% of the respondents in Farta and Konso included the cultural-religious role of chickens rating it fourth in importance whereas all the others did not state the significance of this function (Table 3).

\section{Socio-management factors}

The major management factors describing chicken production in the different regions studied are presented in Tables 4 and 5. All of the households surveyed kept indigenous chickens managed extensively under traditional management regimens. Sixty-two percent of the households in Konso and more than $75 \%$ of the households in Farta, Horro, and Mandura practice supplementary feeding of scavenging chickens whereas confined management of chickens with commercial feeding is not known at all in any of the regions studied. Most of the farmers in the Amhara (Farta, 73\%) and Oromia (Horro, 69\%) regions sheltered chickens in the family house whereas almost equal proportion of those in Mandura and Sheka provided both separate shelter and sheltered in the family house. This is in contrast to Konso, where $80 \%$ of the farmers had separate shelters to house chickens.

Immunization services (Table 5) are almost nonexistent $(95 \%)$ for village chickens in all regions surveyed. However, unlike most of the farmers in the Amhara Region (Farta, 79\%) where treatment of sick birds is not common, most households in Oromia region (Horro, 70\%), and about $50 \%$ of the households in the Southern and BenshangulGumuz regions had awareness of and access to curative medication.

Table 3 Farmers' rating ${ }^{a}$ of the relative importance of different functions of chickens

\begin{tabular}{|c|c|c|c|c|c|}
\hline Functions of chicken & Farta & Mandura & Horro & Konso & Sheka \\
\hline Egg (home consumption) & $3.54(1)$ & $3.47(2)$ & $3.64(1)$ & $3.90(1)$ & $3.91(1)$ \\
\hline Meat (home consumption) & $1.24(3)$ & $3.02(3)$ & $2.76(2)$ & $2.83(2)$ & $3.54(2)$ \\
\hline Cultural/Religious & $0.19(4)$ & 0.00 & 0.00 & 0.19 (4) & 0.00 \\
\hline Source of income & $2.95(2)$ & $4.00(1)$ & $3.64(1)$ & $0.49(3)$ & $3.18(3)$ \\
\hline
\end{tabular}

Numbers in parenthesis indicate ranks based on Wilcoxon signed ranks test. Ranks of chicken functions within a column bearing different numbers are significantly different from each other $(P<0.05)$

${ }^{\mathrm{a}}$ The importance of characters was rated based on weights attributed to each function of chickens by individual respondents; most important $=4$, least important $=1$ 
Table 4 Housing and nutritional management of chickens under the village production system (\% of respondents)

\begin{tabular}{lrrrrrr}
\hline Factor & Farta & Mandura & Horro & Konso & Sheka & Average \\
\hline Housing & & & & & & \\
$\quad$ In the family house & 73 & 49 & 69 & 20 & 58 & 54 \\
$\quad$ Separate shelter & 22 & 51 & 31 & 80 & 42 & 45 \\
$\quad$ Separate house with other animals & 5 & 0 & 0 & 0 & 0 & 1 \\
Management system & & & & & & \\
$\quad$ Indigenous chicken, extensive management & 100 & 100 & 100 & 100 & 100 & 100 \\
$\quad$ Modern chicken, extensive management & 13 & 7 & 11 & 2 & 2 & 7 \\
Nutritional management & & & & & & \\
$\quad$ Scavenging & 22 & 16 & 2 & 38 & 7 & 17 \\
$\quad$ Scavenging+supplement & 78 & 84 & 98 & 62 & 93 & 83 \\
$\quad$ Confined, complete ration & 0 & 0 & 0 & 0 & 0 & 0 \\
\hline
\end{tabular}

There is no systematic mating in any of the regions studied. Thus, breeding of village chickens is completely uncontrolled and replacement stock is produced through natural incubation using broody hens. Whereas only $24 \%$ of the total number of respondents left broody hens to stop this behavior naturally, the remaining majority practiced different methods to modify the broody behavior, in times when incubation was not desired and the hens were required to resume laying faster. Some of the most popular methods reported were: hanging the hen upside-down $(59 \%$ in Horro and $46 \%$ in Konso), moving the hen to neighbor houses (69\% in Farta and 41\% in Mandura). Together, these two are the most important methods commonly practiced by most of the farmers in the surveyed regions. Changing the location of brooding nest is very popular in Konso (42\%), little is known in all other regions (3-9\%).
Traits of adaptive and economic importance

In the discussion among farmers who had adopted modern chickens, the Rhode Island Red (RIR), the most popular and widely adopted chicken in the regions studied, was used as the reference breed. Only data from Farta, Horro, and Sheka were considered because there a relatively larger number of farmers adopted (16\% in Farta, 33\% in Horro, and $25 \%$ in Sheka). In terms of adaptive traits and consumption the indigenous chickens were considered favorable. Most of the respondents claimed that the modern breed is poor in disease and stress tolerance $(86 \%)$ and in the ability to escape predators prevalent in their village conditions (96\%). The modern breed generally required higher level of management $(83 \%)$ often hard to afford and are poor scavengers (86\%) compared to indigenous chick-
Table 5 Health and reproductive management of chickens under the village production system ( $\%$ of respondents)

\begin{tabular}{lrrrrrr}
\hline Factor & Farta & Mandura & Horro & Konso & Sheka & Total \\
\hline Vaccination and immunization & & & & & & \\
$\quad$ No & 96 & 100 & 91 & 98 & 88 & 95 \\
$\quad$ Yes & 4 & 0 & 9 & 2 & 12 & 5 \\
Curative medication & 79 & 50 & 30 & 47 & 51 & 51 \\
No & 21 & 50 & 70 & 53 & 49 & 49 \\
Yes & & & & & & \\
Mating system & 100 & 100 & 100 & 100 & 100 & 100 \\
Uncontrolled, natural & 0 & 0 & 0 & 0 & 0 & 0 \\
Controlled & & & & & & \\
Incubation method & 100 & 100 & 100 & 100 & 100 & 100 \\
$\quad$ Natural (Broody hen) & 0 & 0 & 0 & 0 & 0 & 0 \\
Artificial incubation & & & & & & \\
Broody behavior modification & 12 & 36 & 14 & 13 & 43 & 24 \\
$\quad$ Nothing & 19 & 18 & 59 & 46 & 27 & 33 \\
Hanging upside-down & 69 & 41 & 16 & 0 & 24 & 33 \\
Moving to neighbor houses & 0 & 2 & 2 & 0 & 0 & 1 \\
Submerge into water up to the breast & 0 & 3 & 9 & 42 & 6 & 9 \\
Change brooding place & & & & &
\end{tabular}


Table 6 Farmers' rating of the characteristic attributes of indigenous chickens compared to a reference modern breed $(\mathrm{MB})^{\mathrm{a}}$

\begin{tabular}{|c|c|c|c|c|c|}
\hline Characteristics & Rating & Farta $(\%)$ & Horro $(\%)$ & Sheka $(\%)$ & Total $(\%)$ \\
\hline \multirow[t]{3}{*}{ Disease and stress tolerance } & Superior to MB & 83 & 80 & 95 & 86 \\
\hline & Equal & 0 & 0 & 5 & 2 \\
\hline & Inferior to $\mathrm{MB}$ & 17 & 20 & 0 & 12 \\
\hline \multirow[t]{3}{*}{ Escape from predators } & Superior to MB & 100 & 93 & 95 & 96 \\
\hline & Equal & 0 & 0 & 0 & 0 \\
\hline & Inferior to $\mathrm{MB}$ & 0 & 7 & 5 & 4 \\
\hline \multirow[t]{3}{*}{ Management level required } & Higher & 0 & 36 & 16 & 17 \\
\hline & Lower & 100 & 64 & 84 & 83 \\
\hline & Equal & 0 & 0 & 0 & 0 \\
\hline \multirow[t]{3}{*}{ Scavenging behavior } & Superior to MB & 100 & 80 & 78 & 86 \\
\hline & Equal & 0 & 7 & 11 & 6 \\
\hline & Inferior to $\mathrm{MB}$ & 0 & 13 & 11 & 8 \\
\hline \multirow[t]{3}{*}{ Hatchability of eggs } & Superior to MB & 33.3 & 77 & 90 & 67 \\
\hline & Equal & 33.3 & 8 & 5 & 15 \\
\hline & Inferior to $\mathrm{MB}$ & 33.3 & 15 & 5 & 18 \\
\hline \multirow[t]{3}{*}{ Taste of egg } & Superior to MB & 83 & 93 & 95 & 90 \\
\hline & Equal & 0 & 0 & 0 & 0 \\
\hline & Inferior to $\mathrm{MB}$ & 17 & 7 & 5 & 10 \\
\hline \multirow[t]{3}{*}{ Taste of meat } & Superior to MB & 83 & 93 & 100 & 92 \\
\hline & Equal & 0 & 0 & 0 & 0 \\
\hline & Inferior to $\mathrm{MB}$ & 17 & 7 & 0 & 8 \\
\hline
\end{tabular}

${ }^{\text {a }}$ Rhode Island Red was the reference modern breed $(\mathrm{MB})$

region where comb type affects market price more than plumage color. The type of chicken breed does not have much influence on market preference. The market for eggs is not sensitive to the egg characteristics (egg size and shell color) except that it attached higher preference for eggs of indigenous chickens to those from exotic breeds in all geographic regions (data not shown).

\section{Farmers' selection practices}

All farmers interviewed in the different regions practiced selection on breeding and replacement males and females based on four trait categories: plumage color, live weight, comb type, and "qumena" (Table 8). Similar trait categories are used to select both males and females in all regions. Farmers in the Amhara (Farta) and Oromia (Horro) regions

Table 7 Farmers' rating ${ }^{\mathrm{a}}$ of trait categories/factors most influencing price of live chickens marketed in different regions of Ethiopia

\begin{tabular}{|c|c|c|c|c|c|}
\hline Trait category/factor & Farta & Mandura & Horro & Konso & Sheka \\
\hline Plumage color & $2.04(2)$ & $1.64(2)$ & $2.24(2)$ & 0.80 & $0.96(3)$ \\
\hline Weight & $3.56(1)$ & $3.84(1)$ & $3.04(1)$ & $3.72(1)$ & $3.84(1)$ \\
\hline Comb type & $1.44(3)$ & $1.07(3)$ & $1.60(3)$ & $1.24(2)$ & $1.08(2)$ \\
\hline Breed & 0.00 & 0.00 & $0.88(4)$ & $0.64(4)$ & $0.88(4)$ \\
\hline
\end{tabular}

Numbers in parenthesis indicate ranks based on Wilcoxon signed ranks test. Ranks of trait categories within a column bearing different numbers are significantly different from each other $(P<0.05)$

${ }^{\mathrm{a}}$ The importance of characters was rated based on weights attributed to each character by individual respondents; most important $=4$, least important $=1$ 
Table 8 Trait categories used by farmers to select male and female breeding stock $(\%$ of farmers $^{\mathrm{a}}$ )

\footnotetext{
${ }^{a}$ Percentages do not add up to $100 \%$ since respondents selected based on more than one trait category
}

\begin{tabular}{lllllll}
\hline Trait category & Farta & Mandura & Horro & Konso & Sheka & Total \\
\hline Males & & & & & & \\
Plumage Color & 81 & 57 & 82 & 15 & 35 & 57 \\
Weight & 33 & 55 & 52 & 70 & 54 & 52 \\
Comb type & 40 & 21 & 30 & 36 & 30 & 31 \\
"Qumena" & 12 & 33 & 39 & 24 & 38 & 29 \\
Female & & & & & & \\
Plumage color & 74 & 46 & 61 & 67 & 72 & 58 \\
Weight & 30 & 64 & 12 & 22 & 19 & 20 \\
Comb type & 33 & 14 & 22 & 13 & 3 & 14 \\
"Qumena" & 2 & 30 & & &
\end{tabular}

give the highest emphasis for plumage color while in the Southern region (Konso and Sheka) live weight is used as the most important selection criteria. The emphasis given to each trait category is largely similar across the sexes except that, unlike for males, live weight is most important in Mandura (64\%) and almost equally important to comb type in Farta for selecting breeding females.

Although each of these trait categories consisted of different component traits farmers described the specific trait components for only two of the four trait categories used as selection criteria, plumage color, and comb type (Table 9). White and red plumage colors were identified as the two important component traits used for selecting on the basis of body plumage. Red is the most favored plumage in the Benshangul-Gumuz (Mandura), Oromia (Horro), and Southern Regions (Konso and Sheka), whereas white is the body plumage color more favored by the Amhara community (Farta) irrespective of the sex of the birds. Farmers in the South, however, displayed a much stronger distaste for chickens having white plumage color compared to the others. Similarly, farmers in all regions recognized only two types of combs for the trait category, comb type: "Netela" meaning Single and, "Dirib" that actually comprised all comb types other than "Single" (i.e., rose, pea, walnut, and duplex combs). "Dirib" is a favored comb type both for females $(68 \%)$ and males (90\%) suggesting that most of the farmers placed equally higher preference for any comb type other than single. No specific trait components were identified for the other trait categories, weight, and "qumena," except that all farmers stated that they selected birds that are "heavier," in respect of their age mates, and those having attractive "qumena" judging subjectively by hand "weighing" and visual appraisal.

Effective population size and inbreeding in village chickens

A considerable proportion, ranging from $31 \%$ to $55.6 \%$, of the farmers interviewed in the different regions did not own breeding males. Most of them shared breeding males with neighbors. To get some impression on the effective population size and increase in inbreeding over generations, effective population size were calculated based on the flocks of farmers who possessed their own breeding males. The largest effective population size was recorded in Konso with the subsequent lowest inbreeding coefficient (Table 10).

\section{Rating trait categories for genetic improvement}

Farmers' participatory rating of the importance of different trait categories is presented in Table 11. Adaptive traits (specifically disease and stress tolerance, flightiness, and
Table 9 Farmers' preferences for specific traits in plumage colors and comb types of female (F) and male (M) chickens in different regions (percentage of farmers $^{\mathrm{a}}$ )

${ }^{\text {a }}$ Percentages do not add up to $100 \%$ since respondents in some cases preferred more than one trait

\begin{tabular}{|c|c|c|c|c|c|c|c|c|c|c|c|c|}
\hline \multirow[t]{2}{*}{ Preferred characteristics } & \multicolumn{2}{|c|}{ Farta } & \multicolumn{2}{|c|}{ Mandura } & \multicolumn{2}{|c|}{ Horro } & \multicolumn{2}{|c|}{ Konso } & \multicolumn{2}{|c|}{ Sheka } & \multicolumn{2}{|c|}{ Total } \\
\hline & $\mathrm{F}$ & M & $\mathrm{F}$ & M & $\mathrm{F}$ & M & $\mathrm{F}$ & M & $\mathrm{F}$ & M & $\mathrm{F}$ & M \\
\hline \multicolumn{13}{|l|}{ Plumage color } \\
\hline White & 68 & 76 & 46 & 33 & 19 & 29 & 20 & 6 & 5 & 17 & 32 & 32 \\
\hline Red & 43 & 45 & 68 & 74 & 81 & 86 & 83 & 85 & 90 & 67 & 73 & 71 \\
\hline Any color & 11 & 3 & 4 & 7 & 0 & 17 & 16 & 12 & 15 & 8 & 9 & 9 \\
\hline \multicolumn{13}{|l|}{ Comb type } \\
\hline Single (Netella) & 12 & 6 & 37 & 4 & 25 & 6 & 7 & 0 & 50 & 11 & 26 & 5 \\
\hline "Dirib" & 82 & 94 & 52 & 84 & 75 & 94 & 93 & 100 & 36 & 79 & 68 & 90 \\
\hline Any type & 6 & 0 & 11 & 12 & 0 & 0 & 0 & 0 & 14 & 11 & 6 & 5 \\
\hline
\end{tabular}


Table 10 Possession of breeding males, effective population size, and level of inbreeding of village chicken flock in the different regions

\begin{tabular}{|c|c|c|c|c|c|c|c|c|}
\hline \multirow[t]{2}{*}{ Study area } & \multirow[t]{2}{*}{$\begin{array}{l}\text { Total number of } \\
\text { respondents }(N)\end{array}$} & \multicolumn{2}{|c|}{$\begin{array}{l}\text { Farmers not possessing } \\
\text { breeding males }\end{array}$} & \multirow[t]{2}{*}{$\begin{array}{l}\text { Farmers rearing own } \\
\text { breeding males }(\%)\end{array}$} & \multirow[t]{2}{*}{$\mathrm{Nm}$} & \multirow[t]{2}{*}{$\mathrm{Nf}$} & \multirow[t]{2}{*}{$\mathrm{Ne}$} & \multirow[t]{2}{*}{$\Delta F$} \\
\hline & & $N$ & $\%$ & & & & & \\
\hline Farta & 45 & 18 & 40 & 4.40 & 1.26 & 2.79 & 3.47 & 0.144 \\
\hline Mandura & 45 & 25 & 55.6 & 31.1 & 1.75 & 2.58 & 4.17 & 0.120 \\
\hline Horro & 45 & 14 & 31.1 & 24.4 & 1.84 & 3.76 & 4.94 & 0.101 \\
\hline Konso & 45 & 20 & 44.4 & 22.2 & 1.96 & 3.9 & 5.22 & 0.096 \\
\hline Sheka & 45 & 16 & 35.6 & 15.6 & 1.17 & 2.5 & 3.19 & 0.157 \\
\hline
\end{tabular}

$\mathrm{Nm}$ number of breeding males, $N f$ number of breeding females, $N e$ effective population size, $\Delta F$ inbreeding coefficient

scavenging vigor) in both males and females, growth in males and number of eggs in females, ranked first and equal in importance in low altitudes. In the highlands adaptation is second in importance to growth (males) and egg production (females). Plumage color of birds (low altitude) and comb type (high altitude) were identified as the traits farmers would like the least to be improved in both classes of sex. Farmers in both altitude regimens attributed a comparable and high emphasis to traits related to reproduction in females, even more important than growth. "Qumena" of birds is relatively more important to the farmers in low altitudes than those in the highlands.

\section{Discussion}

Functions of chickens

Like in any other village poultry systems in developing countries, there is no specialized egg or meat chicken production in Ethiopia. Egg production is the principal function of chickens followed by the use as source of cash income and meat. Village chicken in other parts of Africa also played similar roles. In Zimbabwe chickens served as an investment and source of security for households in addition to their use as sources of meat and eggs for consumptions and of income (Muchadeyi et al. 2007). Although previous studies in some parts of Africa (Gondwe 2005; Muchadeyi et al. 2007) indicated that the cultural/ religious role of indigenous chicken types is important, the results of the present study did not support the significance of this function.

Socio-management characteristics and important attributes of indigenous chickens

The village poultry production environment in all geographic regions studied is generally characterized by extensive scavenging management, no immunization pro- grams, increased risk of exposure of birds to disease and predators, and reproduction entirely based on uncontrolled natural mating and hatching of eggs using broody hens. Most of these features were also shared by many other African countries (Aboe et al. 2006; Gondwe and Wollny 2007; Harrison and Alders 2010) although some countries such as Mozambique have started successful vaccination programs against one of the major killer diseases, Newcastle disease (Harrison and Alders 2010). On average, $83 \%$ of the farmers in this study provided supplementary feeding. Recent studies in Ghana and Mozambique also showed that from $90 \%$ to $100 \%$ of farmers offered supplementary feeds to their chickens (Aboe et al. 2006; Harrison and Alders 2010). However, unlike farmers of Mozambique who mostly provided separate shelters and

Table 11 Farmers' participatory rating of trait categories they would like the most to be improved for chickens in low (Mandura) and high (Farta and Horro) altitudes

\begin{tabular}{lll}
\hline Trait category for males & $\begin{array}{l}\text { Low } \\
\text { altitude }\end{array}$ & $\begin{array}{l}\text { High } \\
\text { altitude }\end{array}$ \\
\hline Adaptation & $4.14(1)$ & $3.93(2)$ \\
Growth/weight & $4.14(1)$ & $4.21(1)$ \\
Plumage color & $1.14(4)$ & $3.07(3)$ \\
Comb type & $2.14(3)$ & $1.86(5)$ \\
"Qumena" & $3.43(2)$ & $1.93(4)$ \\
Trait category for females & & \\
Adaptation & $5.14(1)$ & $5.36(2)$ \\
Number of eggs & $5.14(1)$ & $6.00(1)$ \\
Growth/weight & $3.86(4)$ & $3.86(4)$ \\
Plumage color & $1.29(6)$ & $3.57(5)$ \\
Comb type & $2.71(5)$ & $1.64(7)$ \\
Reproduction (broodiness, hatchability of eggs) & $5.00(2)$ & $5.07(3)$ \\
"Qumena" & $4.86(3)$ & $2.50(6)$ \\
\hline
\end{tabular}

Numbers in parenthesis indicate ranks based on Wilcoxon signed ranks test. Ranks of trait categories within a column bearing different numbers are significantly different from each other $(P<0.05)$ 
rarely housed their chickens in their homes (Harrison and Alders 2010) more than $50 \%$ of the farmers in this study housed chickens in the family dwellings at night.

Farmers' ratings of indigenous chickens for various traits/trait categories compared to a reference exotic breed revealed the important adaptive attributes of indigenous chickens. Adaptability of an animal is generally described in terms of traits enabling them to survive, reproduce, and be productive in the limits of their production condition (Parayaga and Henshal 2005). Indigenous chickens were rated to have superior merits with regard to traits such as disease tolerance, tolerance to cold and heat, ability to escape from predators, scavenging, and broody behaviors and hatchability of eggs which are important in adaptation to the village environment; and those traits, such as taste of egg and meat, affecting consumption preference and consequently market value. A review by Islam and Nishibori (2009) indicated that in Bangladesh and many other developing countries, the meat and eggs of indigenous chickens is highly preferred for its taste and suitability for special dishes resulting in even higher market prices for these chickens than their exotic counterpart. Earlier studies on adoption of poultry breeds in Ethiopia (Teklewold et al. 2006) indicated that these trait categories were among the principal factors determining farmers' adoption of improved chicken breeds.

Morphologic traits such as plumage color and comb type were also found to have significant economic values beside other quantitative traits related to growth and egg production. Like in other parts of the world (Jiang 1999), there were specific choices for plumage colors affecting market preferences in the different geographic regions surveyed. The current result indicated that plumage color followed by comb type is only second in importance to live weight in affecting market preference of chickens. In Northern Ethiopia both producer-sellers and intermediary traders attached the highest preference for plumage color. For producer-sellers feather distribution, having either feathered or naked neck is equally important as plumage color followed by breed and comb type whereas for intermediaries comb type is second in importance (Aklilu 2007). The market preferences in this study were based on the opinions of producer-sellers and it was found that very little or no special preference was attributed to the type of breed marketed.

\section{Farmers' selection practices}

Farmers involved in virtually all forms of agricultural production practiced selection of varying scale and intensity for the traits they considered important under their production environment. Village farmers in this study traditionally attached greater selection emphasis to mono- genic qualitative traits, plumage color (white in the Amhara region and red in all the rest) and comb type, next to the only quantitative trait (growth). "Qumena" as a composite trait category mainly deriving from general qualitative characteristics such as conformation is also given an important emphasis. This trait category was described similarly and attributed comparable level of importance in other species of livestock produced by village farmers (Solomon 2008). Similarly, Muchadeyi et al. (2009) reported that poultry farmers in Zimbabwe traditionally selected compact and mature birds rather than angular and tallish ones as breeding stocks though they attached no emphasis to plumage color.

There were almost no differences in the selection of male and female chickens in terms of both the selection criteria employed and emphasis given to the selection traits under the traditional selection practices. The selection practices were limited to trait categories which either influenced market price differentials immediately and directly or observed and/or measured on the selection candidate itself. For instance, although egg production is the most important function of chickens in all households it was not considered as a selection criterion.

However, considering that the trait categories selected in both sexes were consistent to those preferred by the local chicken market, it seems that market of chickens is the principal factor dictating farmers' selection practices in Ethiopia. Lack of information on egg production of the selection candidate was a less likely reason for farmers' not including this trait in their selection criteria because even in the absence of recording, it could have been possible to select the best female and male offspring for egg production at least by recalling the laying performance of their parents which should be simple due to the very small flock size owned per family.

Effective population size and inbreeding in village chickens

The effective population size ranged from 3.19 (Sheka) to 5.22 (Konso) and the number of breeding individuals is very small. The effective population size found in this study was too low compared, for instance, with the average size (15.4) reported for village chickens of Jordan (Abdelqader et al. 2007). Subsequently the rate of inbreeding is quite high in all regions studied here particularly due to the small flock size characterizing this production system, an overall average of 3.4 chickens per household, which is extremely small compared to the average size of 42 reported for Jordan village chickens (Abdelqader et al. 2007) and other African countries such as Ghana, Malawi, Zimbabwe, and Mozambique where it ranged from 13 to 29 (Aboe et al. 2006; Gondwe and Wollny 2007; Muchadeyi et al. 2007; Harrison and Alders 2010). The extremely small flock size 
in this study confirms the drastic drop in the total population of chickens in Ethiopia since the past decade (Dana et al. 2010). On the other hand, though the number of breeding individuals per household is low, the fact that market is also an important source of breeding males might contribute towards reducing further inbreeding. In any case, it should be noted that the estimates on the effective population size as well as rate of inbreeding in the village flocks are not very accurate due to the existing breeding system, which are entirely based on uncontrolled natural mating, and absence of breeding males in many households keeping chickens (see Table 8).

\section{Selection traits and breeding objectives}

Farmers' participatory definition and ratings of the trait categories they liked to be improved were different from those employed traditionally as selection criteria. They included additional economically important traits related to adaptation, egg production, and reproduction. For instance, farmers both in the low altitude (Mandura) and high altitude regions (Farta and Horro) traditionally exerted the highest emphasis on body plumage color next to body weight for selecting males and females. However, following the participatory rating of trait categories, it was one of the traits farmers would like the least to be considered in improving both classes of sex. Adaptation to the production environment was the most important attribute of chickens both in the lowland and highlands in males as well as females (except in the highlands where it is considered second in importance following egg number). Almost similar order of ranking was reported by Muchadeyi et al. (2009) for village chickens in Zimbabwe where farmers across all ecological regions attributed the highest importance to reproductive performance, growth, and survival in the production environment rating plumage color as the least important. In Jordan, village farmers considered egg production as the most important criterion, followed by mothering ability and body weight, for selecting their breeding stock (Abdelqader et al. 2007). Thus, it is advisable to incorporate these traits in the selection schemes while setting up breeding programs targeting village poultry producers in different regions of Ethiopia.

\section{Conclusion}

There is a clear need to base genetic improvement programs for village poultry producers on indigenous chicken genetic resources. This is emphasized by the fact that the adaptive traits in general, and the superior merits of indigenous chickens to high yielding exotic breeds in particular, were rated of the highest significance by the local farmers. Egg production is the principal function of chickens followed in respective order by their use as source of cash income and meat. The market price of chickens is primarily dictated by weight, but farmers rated growth (males) and number of eggs followed by growth (females) as the traits they would like the most to be improved. Therefore, the ultimate breeding goal should be to develop a productive dualpurpose breed that can survive and reproduce under the production environment of village farmers.

Acknowledgments This project is funded by The Netherlands Foundation for the Advancement of Tropical Research (WOTRO). The project is a collaboration between Wageningen University and International Livestock Research Institute (ILRI). We sincerely thank the farmers participated in the project.

Open Access This article is distributed under the terms of the Creative Commons Attribution Noncommercial License which permits any noncommercial use, distribution, and reproduction in any medium, provided the original author(s) and source are credited.

\section{References}

Abdelqader, A., Wollny, C. B. A. and Gauly, M., 2007. Characterization of local chicken production systems and their potential under different levels of management practice in Jordan, Tropical Animal Health and Production, 39, 155-164

Aboe, P.A.T., Boa-Amponsem, K., Okantah, S.A., Butler, E.A., Dorward, P.T. and Bryant, M.J., 2006. Free-range village chickens on the Accra Plains, Ghana: Their husbandry and productivity, Tropical Animal Health and Production, 38, 235-248

Aklilu, H.A., 2007. Village poultry in Ethiopia: socio-technical analysis and learning with farmers, (unpublished $\mathrm{PhD}$ Thesis, Wageningen University)

Besbes, B., 2009. Genotype evaluation and breeding of poultry for performance under suboptimal village conditions, World's Poultry Science Journal, 65, 260-271

Dana, N., Dessie T., van der Waaij, L.H. and van Arendonk, J.A.M., 2010. Morphological features of indigenous chicken populations of Ethiopia, Animal Genetic Resources, 46, 11-23

Falconer, D.S. and Mackay, T.F.C., 1996. Introduction to Quantitative Genetics, (Longman Group, Essex, UK)

FAO (Food and Agriculture Organization of the United Nations), 2008. Poultry sector country review-Ethiopia, FAO Animal Production and Health Division

Gondwe, T.N.P., 2005. Characterization of local chicken in low inputlow output production systems: Is there scope for appropriate production and breeding strategies in Malawi?, (unpublished $\mathrm{PhD}$ thesis, Georg-August-Universitat Gottingen)

Gondwe. T.N. and Wollny, C.B.A., 2007. Local chicken production system in Malawi: Household flock structure, dynamics, management and health, Tropical Animal Health and Production, 39, 103- 113

Gueye, E.F. 1998. Village egg and fowl meat production in Africa, World's Poultry Science Journal, 54, 73-86

Harrison, Jennifer L. and Alders, Robyn G., 2010. An assessment of chicken husbandry including Newcastle disease control in rural areas of Chibuto, Mozambique, Tropical Animal Health and Production, 42, 729-736

IFPRI (International Food Policy Research Institute), CSA (Central Statistical Agency), 2006. Atlas of the Ethiopian Rural Economy, A CD-ROM, (Washington, DC and Addis Ababa) 
Islam, M.A. and Nishibori, M., 2009. Indigenous naked neck chicken: a valuable genetic resource for Bangladesh, World's Poultry Science Journal, 65, 125-138

Jiang, X., 1999. Broiler breeding: breeding goals, selection schemes and the usefulness of local breeds of China, (unpublished $\mathrm{PhD}$ thesis, Wageningen University)

Muchadeyi, F.C., Wollny, C. B. A., Eding, H., Weigend, S., Makuza, M. and Simianer, H., 2007. Variation in village chicken production systems among agro-ecological zones of Zimbabwe, Tropical Animal Health and Production, 39, 453-461

Muchadeyi, F.C., Wollny, C. B. A., Eding, H., Weigend, S. and Simianer, H., 2009. Choice of breeding stock, preference of production traits and culling criteria of village chickens among Zimbabwe agro-ecological zones, Tropical Animal Health and Production, 41, 403-412

Parayaga, K.C. and Henshal, J.M., 2005. Adaptability in tropical beef cattle: genetic parameters of growth, adaptive and temperament traits in a crossbred population, Australian Journal of Experimental Agriculture, 45, 971-983
Scarpa, R., 1999. Revealed preference valuation methods for farm animal genetic material: principles, strengths and weaknesses. In: J.E.O. Rege (ed), Proceedings of an FAO/ILRI Workshop on economic valuation of animal genetic resources, Rome, 1999, (International Livestock Research Institute, Nairobi), 40-47

Solkner, J., Nakimbugwe, H. and Zarate, A.V., 1998. Analysis of determinants of success and failure of village breeding programmes, 6th 4 World Congress on Genetics Applied to Livestock Production, 25, 273-280

Solkner, J., Grausgruber, H., Okeyo, A.M., Ruckenbauer, P., and Wurzinger, M., 2008. Breeding objectives and relative importance of traits in plant and animal breeding: a comparative review, Euphytica, 161, 273-282

Solomon, G.G., 2008. Sheep resources of Ethiopia: genetic diversity and breeding strategy, (unpublished $\mathrm{PhD}$ thesis, Wageningen University)

Teklewold, H., Dadi, L., Yami, A., and Dana, N., 2006. Determinants of adoption of poultry technology: a double hurdle approach, Livestock Research for Rural Development, 18(3), (http://www. cipav.org.co/lrrd//rrd18/3/tek118040.htm) 